\title{
彩 \\ DINÂMICAS INSTITUCIONAIS NO DESENVOLVIMENTO DE MECANISMOS DE E-PARTICIPAÇÃO NOS LEGISLATIVOS NO BRASIL E NO REINO UNIDO
}

\author{
INSTITUTIONAL DYNAMICS AND THE DEVELOPMENT OF E-PARTICIPATION \\ TOOLS BY PARLIAMENTS IN BRAZIL AND THE UK
}

\author{
DINÁMICA INSTITUCIONAL EN EL DESARROLLO DE MECANISMOS DE E- \\ PARTICIPACIÓN EN LEGISLATIVOS EN BRASIL Y REINO UNIDO
}

Isabele Batista Mitozo ${ }^{1}$

\begin{abstract}
Resumo: O artigo tem por objetivo compreender o papel dos setores técnicos nas casas legislativas quanto ao desenvolvimento de ferramentas de e-Participação. A análise é um estudo de caso realizado com duas casas nacionais, a Câmara dos Deputados brasileira e a Casa dos Comuns britânica, a partir de observação em campo e entrevistas com os agentes envolvidos na construção de projetos institucionais online para engajamento público. Como resultados, percebe-se que há uma constante participação de atores externos às casas legislativas contribuindo com o desenvolvimento de inovações digitais para eParticipação, expertise e atualização das equipes que trabalham com esse processo de modernização, que reconhecem a velocidade das mudanças no mundo e acreditam que desenvolver mecanismos para engajamento público online é abrir um canal necessário entre o parlamento e os representados. Por fim, conclui-se que a integração entre setores é um dos pontos essenciais para o sucesso dessas iniciativas, já que abririam portas a uma melhor divulgação e observação múltipla acerca dos problemas a serem superados.
\end{abstract}

Palavras-chave: Servidores do Legislativo; Câmara dos Deputados brasileira; Casa dos Comuns britânica; e-Participação.

Abstract: This paper aims to present the role of officials from parliaments concerning the development of e-Participation mechanisms. The analysis is a case study of two national parliaments - the Brazilian House of Representatives and the British House of Commons - from the observation in field and interviews with public officials involved in the construction of institutional online tools for public engagement. The results show that there is constant involvement of external agents with the institutions to contribute to the modernization process, the teams have expertise and are updated about the world changes concerning digital technologies, and these practitioners believe that developing e-Participation tools is opening an important channel between the parliament and the citizens. Finally, we conclude that the integration between sectors is one of the essential actions to the success of initiatives, since they connect different agents over the same problem and expands the publicity of the mechanisms.

Keywords: Parliament officials; Brazilian House of Representatives; British House of Commons; eParticipation.

Resumen: El artículo tiene como objetivo comprender el papel de los sectores ténicos en las cámaras legislativas en relación con el desarrollo de herramientas de e-Participación. El análisis es un estudio de caso realizado con dos cámaras nacionales, la Cámara de Diputados de Brasil y la Cámara de los Comunes británica, basado en la observación de campo y entrevistas con los agentes involucrados en la construcción de proyectos institucionales en línea para la participación pública. Como resultado, se

\footnotetext{
${ }^{1}$ Professora do Curso de Jornalismo e do Programa de Pós-Graduação em Comunicação da Universidade Federal do Maranhão (UFMA - Campus Imperatriz), Doutora em Ciência Política (UFPR) e Mestra em Comunicação (UFC). Pesquisadora associada ao International Parliament Engagement Network (IPEN). E-mail: ibmitozo@gmail.com
} 
advierte que existe una participación constante de actores externos a las legislaturas contribuyendo al desarrollo de innovaciones digitales para la e-Participación, pericia y actualización de los equipos que trabajan con este proceso de modernización, que reconocen la velocidad de los cambios. en el mundo y creen que el desarrollo de mecanismos para la participación pública en línea está abriendo un canal necesario entre el parlamento y los representados. Finalmente, se concluye que la integración entre sectores es uno de los puntos esenciales para el éxito de estas iniciativas, ya que abrirían puertas a una mejor difusión y observación múltiple sobre los problemas a superar.

Palabras-clave: Consultores legislativos; Cámara de Diputados de Brasi; Cámara de los Comunes del Reino Unido; Participación em línea.

\section{Introdução}

A oferta adequada de mecanismos de input confere maior legitimidade, assim como eficiência às decisões políticas (AVRITZER, 2008; BENHABIB, 1996; ROMANELLI, 2015). Em meio à crise de confiança nas instituições e questionamento de sua legitimidade (LESTONBANDEIRA, 2016), essas instâncias têm desenvolvido de forma crescente projetos para aproximar os cidadãos do centro de decisão política, sobretudo em plataforma digital. Um fator que, todavia, não tem recebido a devida atenção da literatura nesse contexto é que as características de cada parlamento podem exercer influência sobre o modo como essas instituições proporcionam uma abertura à esfera civil, especialmente quando se fala em participação dos representados no processo de construção legislativa.

O trabalho de diversos setores dentro das casas legislativas é de suma importância para o desenvolvimento de ferramentas para engajamento público (LESTON-BANDEIRA, 2007). É por meio deles que projetos são criados, aperfeiçoados e, a partir de habilidades políticas de alguns consultores, conseguem espaço na pauta da mesa-diretora (FARIA, 2012). Desse modo, o presente artigo tem por objetivo analisar o papel dos setores técnicos nesse processo, no sentido de identificar características institucionais que influenciam o cotidiano do desenvolvimento das ferramentas digitais para engajamento e participação. É realizado, para tanto, um estudo de caso da Câmara dos Deputados brasileira e da Casa dos Comuns britânica, dois exemplos de parlamentos que têm destinado equipes à elaboração e à gestão de iniciativas online, identificando toda a estrutura responsável por iniciativas de e-Participação em cada casa e discutindo atores envolvidos, seus papeis no referido processo e a compreensão que os agentes legislativos têm de participação política.

Reconhece-se que não são apenas as características online, diretamente relacionadas às ferramentas, que importam. Sob a perspectiva apontada por Leston-Bandeira (2007), há uma necessidade de se observarem os impactos de características offline dos Legislativos, ou seja, fatores institucionais que exerceriam influência sobre o modo como essas instituições representativas desenvolvem projetos para fomentar, especialmente, engajamento público. Essa argumentação se sustenta, sobretudo, por pesquisas como aquela de Braga, Mitozo e Tadra (2016), que já apontaram para a baixa relação significativa entre variáveis de natureza socioeconômica, externas, e a expressão das funções legislativas por essas instituições por meio 
de seus websites.

Nesse sentido, o artigo discute, primeiramente, as implicações do envolvimento dos setores internos aos parlamentos em análise envolvidos em projetos de e-Participação, a partir de trabalhos já desenvolvidos nessa seara. Na sequência, analisa-se a atuação de servidores dos legislativos nos dois casos nacionais acima destacados, a partir de observações in loco nas casas e de entrevistas realizadas com agentes de setores envolvidos no desenvolvimento de iniciativas digitais para e-Participação nos parlamentos em tela.

\section{Engajamento público e dinâmicas internas parlamentares: relações possíveis}

As Casas legislativas têm utilizado de forma crescente ferramentas de internet para a modernização de processos internos, especialmente em relação à ampliação do engajamento público e da transparência (ROMANELLI, 2015). As mudanças que essa nova dinâmica acarreta aos parlamentos podem resultar em uma redução da distância histórica entre mandantes e mandatários, a partir de um melhor entendimento que os cidadãos podem ter também acerca do funcionamento das instituições.

O crescimento das demandas sociais relacionadas ao processo de engajamento público levou os parlamentos a investirem, especialmente, em três pontos: 1) o provimento de informações acerca da instituição; 2) o desenvolvimento de programas e/ou eventos de educação política pelo legislativo; e 3) a abertura à participação no processo de construção de leis (LESTON-BANDEIRA; THOMPSON, 2015, p. 2). Todavia, as instituições do Estado, sobretudo os parlamentos, são corpos hierárquicos, o que significa dizer que as dinâmicas internas são fatores importantes para o desenvolvimento de ferramentas de participação.

Os estudos, entretanto, não têm se concentrado em investigações para além da estrutura e do uso das ferramentas. Chadwick (2011) é um dos poucos autores que desenvolveram pesquisa mediante observação de dinâmicas institucionais que estão por trás das iniciativas. Rompendo com a tradição de estudar o sucesso de um projeto, o referido autor realizou pesquisa acerca de uma iniciativa que não funcionou conforme se esperava. A ferramenta consistia em fóruns de discussão promovidos pelo Executivo local, em uma grande cidade norte-americana. A estratégia metodológica adotada pela pesquisa consistiu na realização de entrevistas semiestruturadas com gestores e desenvolvedores da ferramenta, por meio das quais se constatou que esse insucesso não se deveu simplesmente ao mecanismo, mas a fatores institucionais que envolveram o processo.

Apesar de a iniciativa ter sido uma ação de um órgão estatal, houve a contratação de uma empresa privada para desenvolver e gerenciar a ferramenta de engajamento. Durante o processo, o projeto sofreu mudanças de direcionamento causadas por fatores inerentes a instituições do poder público. Em primeiro lugar, porque houve (1) cortes orçamentários inesperados, o que comprometeu a continuidade da iniciativa. Consequentemente, gerou-se uma 
(2) instabilidade organizacional no projeto, devida também à (3) terceirização do desenvolvimento e da gestão do fórum. (4) Mudanças nas políticas do órgão também foram fatores negativos para a manutenção do projeto original, às quais o setor privado não pôde se adaptar. A proposta também possuía deturpações, pois o campo político buscava mais controlar que ouvir as demandas da população por meio da iniciativa, ao que Chadwick (2011) chamou de (5) ambivalência política. Por fim, (6) riscos legais e despolitização foram fatores apontados pelos gestores, uma vez que, devido ainda a essa gerência pertencer a uma equipe do setor privado, preocupou-se mais com questões constitucionais técnicas, como a liberdade de expressão e a proteção de dados pessoais, que com o caráter político do debate. Percebe-se, portanto, que uma experiência só pode alcançar sucesso devido a uma matriz complexa de variáveis institucionais.

Na mesma vertente investigativa, Mundkur e Venkatesh (2008) analisam o caso de uma prefeitura na Índia, em que também tomam como variáveis fatores internos ligados à elaboração de mecanismos para e-governança. Nesse caso, os autores se concentraram na relação entre os atores políticos e os atores consultivos, patrocinadores e gerenciadores das ferramentas, respectivamente. Concluiu-se que, embora os funcionários que trabalham com as inovações democráticas digitais para e-governança alcancem, em determinado ponto, um patamar de autonomia para apresentação de ideias e desenvolvimento de novos canais, a visão progressista desses servidores é barrada pelos constrangimentos impostos pelo setor estritamente político. Isso ocorre porque há receios dos representantes quanto às demandas que devem ser atendidas a partir dessa abertura e os resultados políticos que agir insatisfatoriamente pode gerar.

Leston-Bandeira (2007), com uma visão acerca do engajamento público especificamente nos parlamentos, já havia acenado para a possibilidade de estudar essas instituições por dentro. Desse modo, compreender-se-iam as dinâmicas que compõem o processo de promoção de engajamento, indo além da análise da efetividade das ferramentas. A pesquisadora propõe, então, a observação de nove pontos gerais acerca das instituições legislativas que podem influenciar a digitalização de suas atividades, dentre eles: 1) Estrutura de trabalho do parlamento (comissões, recursos); 2) Organização administrativa do parlamento (departamentos e relações entre eles); e 3) Recursos humanos e infraestrutura de que a Casa dispõe (LESTON-BANDEIRA, 2007, p.663). A partir da análise dessas variáveis em trabalho posterior, a pesquisadora apresenta achado interessante sobre o Parlamento Europeu: o papel do Bureau como um motivador das iniciativas de engajamento desse parlamento supranacional. Esse setor foi identificado como um elemento importante do provimento de mecanismos de participação, pois coordena a maioria das ações de tomada de decisão da instituição, como a nomeação de altos cargos administrativos. Uma das ações que o Bureau estimula é o uso das redes sociais digitais para divulgar suas atividades. Essas redes, todavia, também podem proporcionar um canal de duas vias para a comunicação entre o Parlamento Europeu e os 
cidadãos (LESTON-BANDEIRA, 2014, p.426).

A partir dessas evidências empíricas, não se pode ignorar o quanto ainda precisa ser explorado quando se tem em mente, especialmente, a promoção de atividades digitais para engajamento e participação, que exige habilidades específicas. É notável que diversas variáveis podem se encaixar em cada um daqueles grandes fatores apontados por Leston-Bandeira (2007), assim como agregar mais de um deles, conforme pode ser depreendido a partir das características encontradas por Chadwick (2011). Esse também é o caso, por exemplo, da institucionalização apontada pelos estudos como característica que pode garantir o estabelecimento dos projetos como parte efetiva dos processos legislativos. Coleman (2005, p.188) caracteriza esse fenômeno como uma "adaptação institucional de natureza política, procedimental e cultural". Desse modo, a institucionalização das práticas de e-participação envolve, pelo menos, 1) poderes constitucionais, 2) estrutura institucional e 3) estrutura de trabalho dos parlamentos.

Embora grandes investimentos venham sendo realizados nas plataformas para engajamento, internamente as ações dos parlamentos parecem estar ainda desconectadas, o que pode causar vários danos aos projetos. Leston-Bandeira (2014) apresenta quanto às ações dos serviços e setores do Parlamento Europeu que cada um deles começou a criar o próprio perfil nas mídias sociais, o que proporcionou uma audiência muito fragmentada entre esses perfis. Outros parlamentos passam pelo mesmo problema: apesar de a Câmara dos Deputados brasileira, por exemplo, possuir dois websites para comunicação e participação, o Portal da Câmara e o Portal e-Democracia, o contato entre as equipes que os gerenciam para programar ações em conjunto é ação muito recente (FARIA, 2012), vinda a partir da criação do Comitê Gestor de Comunicação, Transparência e Participação (Entrevista com gestores do LabHacker, 2017). ${ }^{2}$

A coordenação eficiente das ações de engajamento e participação dentro dos legislativos se deve, portanto, ao reconhecimento da participação como nova função do parlamento, pois ela se consolidaria nas Casas, expandindo a função de legitimação, ao se observarem os parâmetros estabelecidos por Leston-Bandeira (2007, 2009). Esse fenômeno contribuiria, ainda, para uma maior credibilidade por parte da população representada.

Nesse sentido, muitas questões ainda precisam ser resolvidas, especialmente quando se trata de pensar a relação entre fatores institucionais e as próprias ferramentas de e-participação. Se o descompasso na equipe que gerenciava a ferramenta estudada por Chadwick (2011) foi um dos fatores responsáveis pela descontinuidade do programa, há pistas de que as características estruturais do desenvolvimento e uso de mecanismos desse teor pelas instituições exercem

\footnotetext{
2 O Laboratório Hacker (LabHacker) é uma iniciativa voltada para a promoção de inovações digitais na área de eDemocracia no âmbito da Câmara dos Deputados. Atualmente, o setor é responsável pelo Portal E-democracia, que, dentre outras atividades, gerencia as audiências públicas interativas realizadas pelas Comissões.
} 
influência sobre seu sucesso.

Brasil e Reino Unido apresentam algumas das experiências mais promissoras de engajamento público em plataforma digital. Isso tem atraído atenção internacional desde a digitalização dos orçamentos participativos brasileiros. Esse é um fenômeno a se destacar, pois

[...] com a progressiva tendência à horizontalização e formação de redes que inundou o Brasil na década de 90, aumentaram-se as possibilidades de participação social na elaboração de políticas públicas e exercício de cidadania, como no caso do sempre citado Orçamento Participativo, por exemplo. E esses fatores ganham ainda mais força com o abrupto desenvolvimento da tecnologia de informação (FARIA, 2012, p. 75).

Tendo em conta que a pesquisa aqui desenvolvida partirá da comparação de duas estruturas parlamentares distintas, a seguir, apresentam-se as ações dos parlamentos analisados quanto à gerência de ferramentas digitais de engajamento e participação.

\section{Os casos estudados e suas particularidades}

\subsection{A Câmara dos Deputados Brasileira}

A Casa tem se modernizado e digitalizado, fruto de longa tradição, o que lhe garante capacidade técnica e administrativa para desenvolver rapidamente respostas políticas utilizandose do digital, como ocorreu no período da pandemia de COVID-19, quando as instituições passaram a encontrar-se por meio de plataforma online (PEIXOTO, 2020; MITOZO, 2020). Os setores ligados à comunicação da Câmara com os representados são: a Secretaria de Comunicação (SECOM), o Centro de Informática (CENIN), o Portal da Câmara, o Laboratório Hacker (ou LabHacker, gestor do Portal e-Democracia) e, recentemente, o setor de Dados Abertos, sendo os dois últimos coordenados por uma equipe de planejamento: o Comitê Gestor de Comunicação, Transparência e Participação (MITOZO, 2018).

O Portal da Câmara ${ }^{3}$, no ar desde 1996, constituiu-se como iniciativa inovadora na América Latina. Algo notável é o fato de, desde os primórdios, esse website possuir canais de comunicação direta entre parlamentares e cidadãos, como os bate-papos (MARQUES, 2008). Em 2009, inaugura-se o Portal e-Democracia ${ }^{4}$, ferramenta de participação que aponta o quanto a Câmara dos Deputados brasileira deu passos importantes em um processo que se replicaria em outros parlamentos no mundo, mesmo que em moldes diferentes, pois o e-Democracia é único, o que põe o país em posição de destaque no desenvolvimento desse tipo de mecanismo (FARIA, 2012). A mais recente evolução foi a criação, em 2013, do Laboratório Hacker (LabHacker), um órgão interno à Câmara destinado ao aperfeiçoamento dos projetos online, que, portanto, gere e desenvolve estratégias e canais para o Portal e-Democracia.

\footnotetext{
${ }^{3}$ Dados para acessar o Portal: https://www.camara.leg.br/. Acesso: 06/04/2021.

${ }^{4}$ Endereço eletrônico: http://www.edemocracia.leg.br/. Acesso: 06/04/2021.
} 
Figura 1 - Órgãos ligados ao desenvolvimento de mecanismos de participação na Câmara dos Deputados

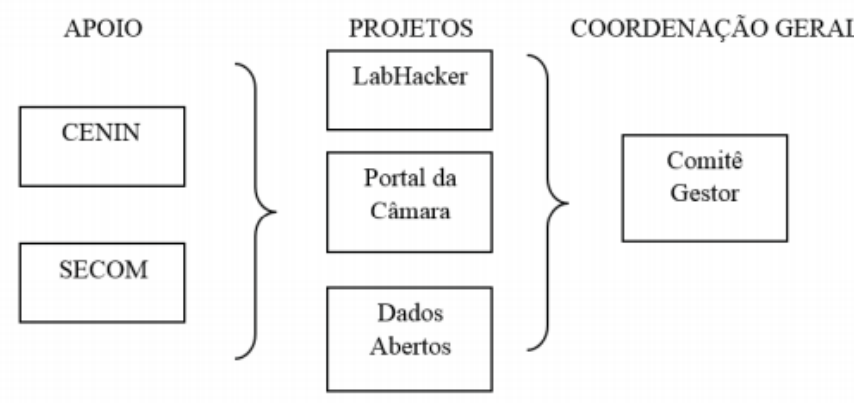

Fonte: Mitozo (2018).

A partir desse infográfico, pode-se perceber que a estrutura de desenvolvimento de participação dentro da Câmara está centrada nos setores mais técnicos, não havendo ligação institucionalizada direta com a esfera estritamente política. Esse fenômeno, então, carece de investigação, uma vez que essa ligação é imprescindível para o sucesso dos projetos. Por outro lado, isso aponta para a importância de instâncias internas aos legislativos no processo de desenvolvimento de mecanismos de abertura participativa e de suas ações para terem conseguido chegar ao estágio em que a Câmara se encontra em relação a essas ferramentas.

\subsection{A Casa dos Comuns Britânica}

Quanto à abertura participativa, desde 2005, essa Casa legislativa tem investido em debates acerca da elaboração de iniciativas online que aproximem o parlamento de seus representados. Em 2006, por exemplo, a Casa decidiu abrir um projeto piloto para expandir-se e alcançar o cidadão. Em 2007, a Comissão de Administração fez uma reunião que colocava como pontos a serem melhorados em relação ao acesso dos cidadãos ao parlamento: 1) a modernização do website da instituição, 2) programas para levar o parlamento para fora de seu espaço físico, e 3) programa de visitas guiadas dentro do Palácio de Westminster. A partir da formalização dessas necessidades, instaurou-se o setor de Parliament Outreach Services (POS) ${ }^{5}$, tornando-se permanente na Casa, uma vez que "simplesmente prover informações sobre o parlamento é pouco para uma conexão entre cidadãos e instituição" (LESTON-BANDEIRA, 2016, p. 19), seguindo as novas metas de um parlamento que incorpora o objetivo de alcançar todos os seus representados.

Após ter sido desenvolvida uma espécie de Consulta Pública online acerca das leis de infância no Reino Unido em 2013, a Public Reading, foi elaborada uma iniciativa importante para o aperfeiçoamento das atividades de digitalização do parlamento britânico. O Comitê de Democracia Digital (DDC) do Speaker, então, idealizado e liderado por John Bercow ${ }^{6}$, em

\footnotetext{
${ }^{5}$ Esse é o órgão que promove serviços educacionais sobre o Parlamento britânico com atividades tanto fixas, nas próprias Casas do Parlamento, quanto itinerantes.

6 De acordo com dois entrevistados, o Speaker (Presidente da Casa dos Comuns) à época "burlou" a legislação
} 
meados de 2013, foi uma instância especial que trabalhou entre o início de 2014 e de 2015, coletando percepções, reunindo tanto especialistas quanto cidadãos em debates (ele próprio tinha uma formação mista, com parlamentares, acadêmicos, empresários de Start-ups de tecnologia e representantes da sociedade civil organizada ${ }^{7}$ ), a fim de traçar objetivos práticos para que esse parlamento pudesse melhorar os mecanismos de que já dispunha, assim como seu alcance.

Desse modo, em janeiro de 2015 foi lançado o relatório final desse Comitê consultivo, intitulado Open Up!, que apresentava cinco recomendações principais, metas a serem alcançadas pelo parlamento em cinco anos: 1) até 2020, a $\mathrm{HoC}$ deveria garantir que todos os cidadãos compreendessem o que ela faz; 2) até 2020, o parlamento deveria se tornar totalmente interativo e digital; 3) A HoC eleita em 2015 deveria criar imediatamente um novo fórum de participação pública para debater as funções da instituição; 4) até 2020, o voto online seguro deveria ser uma opção para todos os eleitores; 5) até 2016, toda informação publicada e toda transmissão produzida pelo parlamento deveria estar disponível gratuitamente online em formatos próprios para reutilização (DIGITAL DEMOCRACY COMMISSION, 2015). Os documentos da Hansard ${ }^{8}$ deveriam estar disponíveis como dados abertos até o final de 2015. Nem todas essas metas foram cumpridas, sobretudo quanto ao voto digital, uma das maiores resistências em relação à digitalização no Parlamento Britânico9.

A partir de então, dedicou-se maior atenção aos projetos de cibercâmara, como a criação de uma equipe especializada para lidar com a gerência de atividades online e offline, a Your UK Parliament, como a utilização do Twitter para divulgação e discussão de atividades (@YourUKParl) e pautas da Casa e a organização da Semana do Parlamento ${ }^{10}$, respectivamente. Todas as atividades desse teor, contudo, só podem se desenvolver devido ao apoio de dois órgãos centrais no Parlamento: Parliamentary Digital Services, equipe de tecnologias digitais da Casa, e Parliament Outreach Services. Esses órgãos são responsáveis, sobretudo, pelas ações de educação acerca do parlamento e também por ações presenciais de engajamento público, como visitas guiadas às Casas do Parlamento Britânico. A partir da investigação dos componentes do provimento de mecanismos, tanto online quanto offline há alguns anos, nesse parlamento, a estrutura que se pode depreender apresenta-se de forma sistemática na figura abaixo $^{11}$.

interna da Casa acerca do processo de instauração de um Comitê misto, a fim de constituí-lo o mais rápido possível.

7 A lista dos integrantes do DDC está disponível em: https://www.parliament.uk/business/commons/thespeaker/speakers-commission-on-digital-democracy/members/ Acesso: 06/04/2021.

${ }^{8}$ Hansard é o órgão responsável pela compilação dos debates, discursos e reuniões do Parlamento Britânico.

${ }^{9}$ Mesmo em relação ao próprio voto online dos MPs, há grande resistência, uma vez que é um ritual importante de contato entre parlamentares e ministros. Disponível em: https://www.theguardian.com/politics/2020/jun/02/mps-join90-minute-long-queue-to-vote-to-end-virtual-voting Acesso: 10/04/2021.

10 Evento que promove o engajamento do público com as atividades das Casas. Disponível em: https://www.ukparliamentweek.org/en/. Acesso em: 11/04/2021.

11 Deve-se ressaltar que o sistema de petições não foi inserido no corpus da pesquisa e, portanto, não aparece como 
Figura 2 - Órgãos ligados ao desenvolvimento de mecanismos de participação na House of Commons

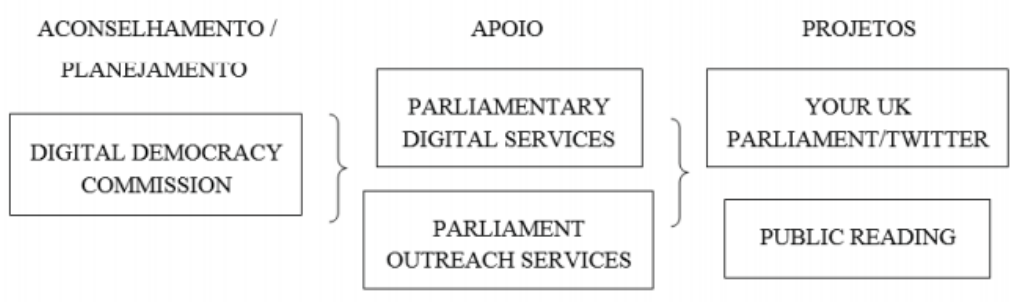

Fonte: Mitozo (2018).

A observação do conjunto de setores e projetos apresentados acima permite afirmar que a Casa dos Comuns britânica tem trabalhado em um processo de modernização de suas atividades, especialmente as estratégias de engajamento público pelo meio digital. Se ainda há receio quanto ao voto digital dentro da Casa, isso se deve a uma mentalidade mais procedimental de como ela funciona, o que aponta para uma mudança na regulamentação interna, na legislação e, consequentemente, nos ritos seguidos por séculos durante as sessões na Casa, para que seja dada maior importância aos projetos de digitalização e institucionalização da participação pós-eleitoral nessa Câmara.

\section{Estratégias metodológicas}

Este trabalho tem como objetos de análise os elementos relativos ao desenvolvimento de iniciativas participativas online nos parlamentos brasileiro e britânico, especificamente, em suas câmaras baixas: Câmara dos Deputados (BR) e Casa dos Comuns (UK). O objetivo é identificar características institucionais relacionadas aos setores internos que influenciam o cotidiano do desenvolvimento das ferramentas digitais para engajamento e participação.

A partir da literatura, percebe-se que essas duas Casas legislativas estão entre os maiores expoentes em iniciativas de democracia digital, mas, o que mais chama atenção é a ausência de outras iniciativas promovidas por parlamentos que abram espaços permanentes de debate ou que possuam equipes direcionadas ao planejamento de canais e estratégias, como encontrado nos casos em foco na figura do Laboratório Hacker (Brasil) e do Comitê de Democracia Digital (Reino Unido).

Desse modo, parte-se da seguinte questão de pesquisa: como arranjos internos compõem o desenvolvimento de ferramentas para engajamento público online? A fim de responder a esse questionamento, foram, então, realizadas entrevistas com agentes conectados aos projetos de participação, tanto no âmbito técnico quanto parlamentar, nas duas Casas. O método adotado foi o da entrevista semiestruturada, uma vez que havia necessidade de um roteiro, mesmo que esse devesse ser flexibilizado no decorrer da conversa, a fim de permitir

projeto nesse quadro, por constituir-se como ação conjunta entre Parlamento e Governo. Isso dificultaria a observação das dinâmicas internas como fatores influenciadores do processo, uma vez que também deveriam ser investigadas as características do Executivo, o que fugiria do escopo da investigação conduzida. 
melhor "diálogo com o entrevistado, aprofundando aspectos importantes para a compreensão de seu pensamento [...] sobre os assuntos em pauta" (VEIGA; GONDIM, 2001, p. 5). As narrativas desses personagens importam (PRIOR, 2017) e são fontes importantes para o esclarecimento de características como hierarquia e o "complexo jogo entre diferentes atores e interesses em uma dada organização" (CHADWICK, 2011, p.23).

Após um mapeamento dos setores e de seus principais atores, assim como um contato prévio com esses agentes, por e-mail ou chat online, foram realizadas quatro entrevistas no parlamento britânico e duas na Câmara dos Deputados. No Parlamento britânico, além de duas consultoras (Lucinda Blaser e Tracy Green) e um consultor (Edward Wood), chamados officials, entrevistou-se uma parlamentar, Meg Hillier, que integrou o Comitê de Democracia Digital (DDC) e que ocupava o cargo de Presidente da Comissão de Controle de Contas Públicas durante a 56 ${ }^{\mathrm{a}}$ legislatura (2015-2017), período em que as entrevistas foram realizadas. A partir disso, é possível compreender motivações e estratégias da Casa para pensar projetos de democracia digital, tais como o DDC e as práticas de Cibercâmara recomendadas por esse comitê, e como os parlamentares reagiram à prática desses projetos. As entrevistas foram realizadas no Parlamento Britânico, entre janeiro e fevereiro de 2016.

No Brasil, realizaram-se duas entrevistas, uma com a coordenação do LabHacker, órgão que atualmente desenvolve e gere o Portal e-Democracia na Câmara, e outra com o Deputado Ricardo Tripoli, um dos parlamentares que compôs a equipe do processo de discussão e criação do Portal e-Democracia, em meados de 2008. As entrevistas foram realizadas, respectivamente, nos dias nove e dezesseis de março de 2017, na própria Câmara. A primeira delas aconteceu no próprio LabHacker, em um momento menos agitado no setor, quando puderam ser reunidos os três principais gestores: Cristiano Faria, Simone Ravazolli e Walternor Brandão. Quanto ao deputado, o contato foi estabelecido a partir de dois assessores de gabinete do parlamentar. Devido à agitação da semana de possível votação de projeto polêmico (Reforma da Previdência) e uma viagem do deputado antecipada por um imprevisto, tendo em vista que o entrevistado era, então, líder de seu partido na Câmara, a conversa foi realizada por telefone, a partir do LabHacker.

As entrevistas foram analisadas por meio do software Nvivo, pela possibilidade de se identificarem de forma mais precisa as seguintes categorias: 1) atores mencionados e sua origem (a instituição patrocinadora da iniciativa, partido político, setor técnico, sociedade civil organizada, deputado/MP, academia, business, outra); 2) papel de atores mencionados; 3) o papel da(o) entrevistada(o) em relação às práticas participativas da instituição legislativa à qual pertence (ou pertencia à época da entrevista); 4) expectativas da(o) entrevistada(o) acerca de melhorias na instituição e na democracia proporcionadas por projetos de participação; 5) visão acerca do(s) projeto(s) de que faz parte; 6) conceito/compreensão de participação do(a) entrevistado(a). 
A fim de complementar as informações coletadas tanto por meio de documentos quanto das entrevistas, realizou-se como técnica auxiliar, ainda, uma breve observação das rotinas de trabalho dentro dos dois parlamentos. Ela ocorreu brevemente em dois dias na Casa dos Comuns, dezesseis de janeiro e oito de fevereiro de 2016 (em decorrência da oportunidade das entrevistas e de uma reunião de avaliação das ações da Casa frente às recomendações da Comissão de Democracia Digital) e durante nove dias na Câmara dos Deputados brasileira, entre seis e dezesseis de março de 2017, especificamente no LabHacker, que coordena as atividades participativas online nessa Casa.

Desse modo, além das entrevistas identificadas, têm-se registros de conversas informais com servidores(as) durante esses dias, sem que esses(as) profissionais estejam identificados(as) quando da menção de trechos de diálogos informais no decorrer do trabalho. Vale ressaltar que o uso desses trechos foi consentido pelos agentes, desde que não fossem identificados no trabalho. Essas conversas contribuíram para uma visão mais ampla dos processos, o que será apresentado na análise, a seguir.

\section{Análise}

\subsection{Características do envolvimento dos setores internos aos legislativos com o desenvolvimento das ferramentas}

As entrevistas realizadas na Câmara dos Deputados apresentaram alguns agentes como importantes no processo de desenvolvimento das iniciativas de engajamento. Atores institucionais (Executivo, Judiciário, TV e rádio Câmara, Comissões, deputados, Secretaria de Comunicação da Câmara - SECOM, Centro de Informática - CENIN, Comitê Gestor do Portal da Câmara, presidente da Câmara, Departamento de Taquigrafia, Diretoria Geral, Senado), acadêmicos (universidades, prof. Rafael Sampaio, prof. Wilson Gomes), da sociedade (hackers, Operação Serenata de Amor ${ }^{12}$ ) e de outras instituições representativas (Câmara de Deputados do Distrito Federal) contribuíram com os projetos da Câmara. O papel que exerceram se constituiu de uma parcela de responsabilidade quanto à publicidade do Portal e-Democracia, à compreensão dos objetivos de projetos de e-participação, à concretização de debates online e, ainda, ao estímulo de mais ações por parte da Câmara por inspirar novos projetos fora de seus limites físicos, como o novo portal participativo da Câmara Distrital. Deve-se ressaltar, entre esses agentes, os últimos presidentes da Casa, que lideraram projetos de abertura participativa: Câmara Itinerante (2015) - Eduardo Cunha - e Câmara Aberta (2017) - Rodrigo Maia.

Os entrevistados, alguns deles também mencionados nas outras conversas, possuíam papel de destaque em relação aos projetos de engajamento e participação online das Casas em estudo. No caso brasileiro, a equipe do LabHacker, gestora do Portal e-Democracia, é composta

\footnotetext{
12 A Operação Serenata de Amor é um projeto que desenvolveu uma "inteligência artificial para controle social da Administração pública”, a qual analisa, especificamente, notas fiscais referentes aos gastos dos deputados pelos quais foi solicitado reembolso. Disponível em: https://serenata.ai/. Acesso: 10/04/2021.
} 
por duas chefias: o diretor do laboratório e a coordenadora das ações do portal. Na ocasião da conversa, a coordenação do portal estava em fase de transição, logo, o recém ex-coordenador também foi convidado a participar, mesmo porque continuava sendo funcionário do setor e desenvolvendo projetos junto à equipe de programação. É importante mencionar que a nova coordenadora do portal brasileiro em estudo já havia sido jornalista da Secretaria de Comunicação da Câmara, órgão responsável por publicizar as atividades da Casa. O deputado entrevistado foi um dos componentes da comissão que discutiu e aprovou a implantação do Portal e-Democracia, em meados de 2008. No momento da pesquisa, o parlamentar ocupava a liderança de seu partido na Câmara.

Esses entrevistados apresentaram uma visão bastante positiva da iniciativa, embora tenham sido expostos os desafios e as limitações do trabalho dentro da Casa.

Hoje, parlamentares da direita e da esquerda chegam muito crentes de que esse é
o caminho. Não sabem ainda como usar, não sabem adotar isso, mas sabem que é
inevitável. Sabem que estamos realmente em um momento de transição. Então,
para mim é muito legal ver que o trabalho se consolidou. Tem muito ainda o que
fazer, a gente ainda está no começo. Acho que o melhor ainda vai vir e que ainda
estamos bem longe dessa ideia. Mas, muita gente se inspira nisso, está indo atrás,
fazendo. E eu não falo só do [portal] e-Democracia, mas de todo o trabalho que
está sendo construído aqui na Câmara. E é um trabalho resultante de outros
órgãos, de outras pessoas. Isso está repercutindo muito, aqui, no vizinho do lado
(estávamos na Câmara Distrital ajudando a inaugurar o LabHacker de lá)
(Cristiano Faria. Entrevista com gestores do LabHacker, 2017).

Os desenvolvedores e gerentes da ferramenta brasileira acreditam na participação como a criação de um canal de comunicação entre as esferas civil e política, com a realização de um feedback por parte dos deputados, ou seja, "o cidadão sabendo que está sendo ouvido, o deputado recebendo essa informação e reforçando que ouviu" (Simone Ravazolli. Entrevista com gestores do LabHacker, 2017). Isso, segundo eles, é componente da democracia e envolve, ainda, um processo de abertura que parta de informação e transparência para ampliar as atividades de engajamento e participação. A partir desses incrementos, os cidadãos podem enviar colaborações para que as discussões legislativas resultem produtos melhores.

Nas conversas na Casa dos Comuns, percebe-se que a lista de atores mencionados segue de perto aqueles mencionados em documentos oficiais, o que prova que esses são agentes que, de fato, tiveram importância para o desenvolvimento de projetos de engajamento, especialmente aqueles de e-participação. Eles estão entre movimentos da sociedade civil (Mind, organização que trabalha com pessoas com deficiência mental; Mysociety, que trabalha com projetos para cidadania; WeNurses, organização de enfermeiras), integrantes do DDC (Hellen Milner, da Tinder Foundation; Justine McGuiness, coordenadora de mídia de John Bercow na época em que ele era presidente da Casa, que auxiliou os trabalhos iniciais do DDC), órgãos ligados ao parlamento ou coordenados pela instituição (Comissão de Modernização, Governo, Comissão de Negócios Internos, DDC, PDS, Setor de Arquivo), outras instituições políticas (Scottish 
Nationalists). O papel que esses agentes mencionados têm exercido junto ao parlamento e, especificamente, à Câmara representativa do parlamento britânico consiste na agregação de expertise e participação em atividades de engajamento.

Houve uma menção a uma empresa multinacional (Coca-Cola) para falar da humanização dos perfis do parlamento nas redes sociais digitais (como a utilização do perfil de um personagem chamado "Bob" para se comunicar com o público representando a referida marca). Essa menção demonstra que as equipes de desenvolvimento e gerência de engajamento e participação estão atualizadas e se baseiam em experiências externas e alheias ao campo político para pensar suas próprias atividades.

Quanto aos entrevistados e suas funções, a parlamentar ocupou uma das três cadeiras no DDC destinadas aos Membros do Parlamento (MPs) e é uma das encorajadoras de atividades em ambiente digital para engajamento público. O consultor foi secretário do DDC e atua no setor de informação do Parlamento Britânico. Sua função durante os trabalhos da comissão especial foi coordenar as atividades, especialmente no período inicial de debates internos e formação da comissão. Uma das consultoras entrevistadas falou de modo específico sobre seu papel dentro das ações de engajamento público via online na Casa.

Eu trabalho na equipe de Digital Outreach (alcance digital) e nós fazemos coisas como social media das contas de Twitter da Casa dos Comuns e da "UKParl", fazendo live tweeting, negócios e as stories para o website sobre o que está acontecendo na Câmara, divulgando informações sobre projetos de lei assim como fazendo meu trabalho específico, que é o maior alvo: fóruns fora do parlamento que funcionam a partir do engajamento em espaços digitais, onde as pessoas já estão. [...] Então, eu estive trabalhando nas ações de cibercâmara, que eu lidero, mas minha equipe também tem trabalhado com a terminologia, a elaboração de um glossário. Nós atualizamos completamente, assim como o formato dos tweets da Casa (Lucinda Blaser. Entrevista, 2016).

Do mesmo modo, a terceira entrevistada, consultora do Parlamento à época, afirmou que sua equipe também trabalhava com o monitoramento de hashtags, mas em relação aos perfis das Comissões do parlamento, tendo sido gestora de uma das discussões online promovidas pela Casa. Entre outras funções, foram elencadas: manutenção tecnológica de conexão da Casa e planejamento de projetos.

Você tem a equipe cuidando do departamento de ajuda e lidando com problemas tecnológicos que vão acontecendo. A equipe também gerencia todo o kit tecnológico que os MPs utilizam (desktops, laptops, impressoras etc.) e há pessoas que mantêm a rede e garantem que o Wi-Fi funcione. Então, você tem a equipe que está focada em todo o planejamento de projetos, que chamamos de equipe de portifólio (Tracy Green. Entrevista, 2016).

Esses atores institucionais apresentaram expectativas e visão dos projetos que integram, principalmente em relação a como essas ações podem contribuir para melhorias nas instituições e na democracia. Lucinda Blaser, dos Parliament Outreach Services (POS), afirma que ainda há barreiras a serem transpostas, mas que as iniciativas são boas oportunidades de abrir espaço para 
ouvir as demandas da população, como a ação de receber ensaios de até 3.000 palavras dos cidadãos, promovida pelos POS.

Outro ponto levantado nas entrevistas é o fato de que o fenômeno da modernização e da abertura participativa deve ser abraçado por todo o parlamento, desde as equipes consultivas aos próprios parlamentares, a fim de construírem iniciativas mais eficientes. Isso significa

[...] habilitar o Parlamento a fazer um bom uso real da tecnologia no modo como ele se engaja com os cidadãos, como pode ser mais transparente e aberto sobre o que acontece aqui, e por que isso importa às pessoas, e como ele pode se engajar com elas. Mas também, em termos construção de capacidade, a equipe que trabalha aqui, desenvolvendo suas habilidades e expertise digital, assim como os(as) MPs (Tracy Green. Entrevista, 2016).

As expectativas dos officials da Casa dos Comuns consistem em ver essas iniciativas completamente diferentes em vinte anos, tendo em vista "a velocidade com que as mudanças têm acontecido", como cita Green, mesmo em face da enorme dependência que as ações desses atores têm em relação aos MPs. Do mesmo modo, acredita-se que MPs devem engajar-se com os projetos, tentando ganhar conhecimento acerca deles, embora não se deva exigir que os parlamentares precisem ser especialistas em cada um dos temas suscitados ${ }^{13}$.

A compreensão de engajamento e participação que pôde ser obtida a partir das conversas com servidores e parlamentares é que eles esperam projetos de engajamento digital como aqueles em que as pessoas podem dizer o que pensam (FOX, 2009). Consideram, todavia, um desafio ainda grande incorporar essas demandas, devido às restrições da própria Casa, ou mesmo prover responsividade sobre o fato de as contribuições não serem acatadas. Essa é uma preocupação que parte, sobretudo, da MP entrevistada.

Percebe-se, a partir desta análise, que as dinâmicas internas às Casas Legislativas são mais que acessórias ao desenvolvimento de iniciativas de participação, especialmente aquelas em ambiente digital: essas características ganham papel central no processo. A seção seguinte, concentra-se em discutir uma das características-chaves encontradas: a integração entre setores das casas legislativas no desenvolvimento de ações online para engajamento público.

\subsection{A integração dos setores no processo de abertura participativa}

Percebe-se a partir da análise dos agentes e seus papéis na dinâmica de modernização dos parlamentos que o campo político não parece ser o único ponto problemático na implantação de mecanismos participativos nos parlamentos (FARIA, 2012; MITOZO, 2018). As relações que os setores ligados a essas ações mantêm são bastante importantes para o desenvolvimento de iniciativas. Por exemplo, a Secretaria de Comunicação da Câmara dos

\footnotetext{
${ }^{13}$ Essa é uma função que cabe aos Lordes, os quais, ao contrário dos MPs, possuem uma formação específica muitas vezes distante da Política. Além do mais, eles não precisam se dedicar completamente à política, no sentido de que não precisam fazer campanhas ou atenderem a demandas de eleitorados específicos, pois não são detentores de cargos representativos.
} 
Deputados (SECOM) não se conecta muito ao Portal e-Democracia/LabHacker. Como consequência, atualmente, essa secretaria não publiciza apropriadamente as ações desse projeto. Um exemplo dessa falta de ligação ocorreu enquanto a pesquisadora estava em estágio de observação, no LabHacker: a SECOM publicou um tweet sobre o lançamento da nova versão do Portal e-Democracia às $23 \mathrm{~h}$.

Isso foi motivo de uma discussão entre os dois setores, o que foi presenciado pela pesquisadora. "[Essa iniciativa] está inserida no projeto 'Câmara Aberta' que o presidente [da Casa] está lançando. Aí você vê a falta de conexão [entre os setores]!”, disse um consultor legislativo. Não se pode deixar de mencionar que a SECOM não estava em serviço na hora da publicação. Mesmo assim, a programação para esse post de publicidade do portal ficar para um horário em que não haveria público suficiente, e tendo em vista que as postagens na rede Twitter se "perdiam" facilmente, pois a ferramenta ainda seguia uma sequência cronológica à época, é fator sintomático.

A integração entre setores nos Legislativos é um ponto problemático, especialmente por causa da burocracia. Ainda em relação ao Brasil, a Comissão de Legislação Participativa (CLP), a mais importante ação offline permanente para participação cidadã, tem um regulamento bastante restritivo, o que a leva a trabalhar nos moldes dos movimentos sociais dos anos 1990, com material impresso. Essa é uma ação usual na CLP mesmo após vinte anos de existência (2001-2021). No entanto, os processos dessa Comissão poderiam ser conduzidos mais facilmente se houvesse uma integração com o Portal e-Democracia.

Em 2016, foi aberta uma Comunidade Legislativa no portal nomeada CLP ${ }^{14}$. De acordo com um dos gestores do e-Democracia, essa ação foi interessante, pois houve um planejamento para desenvolver os canais que atendessem às demandas da CLP para as discussões disponibilizadas e, ainda, uma parceria com pesquisadores e universidades, a fim de pensar estratégias melhores.

\begin{abstract}
Mas o projeto acabou não avançando por outras questões, que não foram impedimentos tecnológicos ou por problema de relacionamento da CLP. A aproximação foi interessante, a ideia era boa, mas precisa fundamentalmente de uma reforma no regimento interno da CLP, para rever algumas dessas coisas e esse é um gargalo na inovação, porque inovação algumas vezes vai bater justamente na legalidade (Walternor Brandão. Entrevista com gestores do Labhacker, 2017).
\end{abstract}

Desse modo, percebe-se que, apesar de ter se constituído um passo importante para a digitalização, agilização dos trabalhos e integração entre órgãos com objetivos semelhantes, essa atividade não será uma tendência, uma vez que o foco da CLP não é tratar com os cidadãos de forma individualizada, como o e-Democracia propõe. Essa comissão permanente dialoga com a sociedade civil organizada.

14 Disponível em: http://arquivo.edemocracia.camara.leg.br/web/clpdigital/inicio\#.YJmdIO2Sk2x. Acesso em 10/05/2021. 
Quem pode apresentar Sugestões Legislativas? Organizações não-governamentais (ONGs); Associações e órgãos de classe; Sindicatos; Entidades da sociedade civil, exceto partidos políticos; Órgãos e entidades de administração direta e indireta, desde que tenham participação paritária da sociedade civil (CÂMARA DOS DEPUTADOS, 2013, p.14).

Ademais, o sistema de registro de atividades da CLP, essencialmente as Atas, são mecanismos ainda de cunho presencial, tradicional (CÂMARA DOS DEPUTADOS, 2013), o que chama mais atenção para a necessidade de mudança dos regimentos internos à Casa brasileira. Esse é um dos fatores que justificam a declaração anônima de um servidor em relação a outros setores e, especialmente, ao campo estritamente político: "não atrapalhando, já temos um grande avanço".

Por outro lado, o projeto Câmara Itinerante, de 2015, proporcionou uma integração entre a equipe gestora do e-Democracia e a SECOM, pois havia uma divulgação intensa da agenda da iniciativa, tendo em vista o fato de que o presidente da instituição à época liderava as caravanas do projeto às unidades da federação.

[...] em todas as edições do canal itinerante que aconteceram, o [portal] e-Democracia esteve presente, tinha transmissão ao vivo do que acontecia a partir da SECOM, e tinha interação via Portal e-Democracia. Os índices de participação foram muito bons, tinha fluxo de participação acima da média no Portal e-Democracia. E uma coisa bem legal que havia nesse projeto também eram os relatórios. Então, toda a participação, todo evento, a cada edição, gerávamos um relatório que era entregue para o presidente e para todo mundo que participou ali. Isso para haver uma noção de como foi essa participação, o que trouxe o ganho de evidenciar o potencial da ferramenta (Walternor Brandão. Entrevista com gestores do LabHacker, 2017).

Percebe-se, portanto, que a integração gerou boas consequências para as discussões a partir do portal estudado. É fato que os setores envolvidos na iniciativa ocupam um lugar de destaque na promoção e no desenvolvimento desses projetos. Por isso, o modo como articulam seus interesses, a partir de sua diversidade de visões de parlamento e representação, é um ponto importante para o estabelecimento de uma cooperação interna.

O Parlamento britânico recentemente tem articulado equipes internas direcionadas à coordenação de mecanismos digitais de engajamento público. Assim, pode-se dizer que há investimentos sendo realizados. A Casa dos Comuns, entretanto, ainda não centraliza os trabalhos de engajamento e participação online em uma só equipe de coordenação das atividades, pois faz uso de todos os setores que trabalham com informação, educação parlamentar e recursos digitais. O Parliamentary Digital Service (PDS) e os Parliament Outreach Services (POS) buscam, por meio de ações offline e online, coletar o que os cidadãos pensam acerca de assuntos concernentes à Casa ou em discussão nas etapas de discussão de projetos, as chamadas "leituras". Essa unificação dos setores em torno de um objetivo aponta para um cuidado com o desenvolvimento da digitalização do parlamento, especialmente, da Casa dos Comuns, já que é a instituição representativa, da qual os cidadãos podem cobrar ações. 
A própria reformulação do antigo departamento Parliament ICT como PDS mostra como a instituição tem apostado na ideia de se modernizar indo além de um investimento em estrutura tecnológica, mas com uma preocupação mais voltada aos resultados, ou seja, com o que se colherá a partir das ações promovidas por ela em ambiente online.

[...] previamente o Parliament ICT era muito focado em Tecnologias de Informação e Comunicação, i.e., muito concentrado em cabos, computadores, e não era muito sobre resultados que poderia alcançar [por meio de suas ações]. Então em acho que unido esse setor à equipe web e redirecionando o foco para o digital é algo positivo. [...] No coração disso, há duas coisas: a primeira é sobre permitir ao Parlamento realizar um uso realmente bom da tecnologia no sentido de engajar os cidadãos e de promover mais transparência e abertura sobre o que acontece aqui, em que isso influencia a vida das pessoas e como elas podem se engajar (Tracy Green. Entrevista, 2016).

É importante ressaltar que, a fim de oferecer maior compreensão acerca do parlamento e de como os cidadãos podem interagir com ele, essa parceria entre PDS e POS deu origem a uma equipe conjunta para divulgação e gerência de algumas atividades de engajamento público, a Your UK Parliament, conforme apresentado anteriormente.

Por meio do DDC, a Casa dos Comuns, além de escutar as sugestões e pedir consultoria de agentes externos (professores, empresários, estudantes etc.) para o desenvolvimento de suas ações, tentou reunir profissionais de diferentes órgãos da Casa. Alguns officials foram, então, nomeados pelo presidente como integrantes desse Comitê. Eles seriam responsáveis por relatar as atividades e pensar a aplicação das recomendações, tarefas sobre as quais seriam arguidos mais adiante em evento público na Casa, que ocorreu no dia oito de fevereiro de 2016.

As ações de abertura participativa da instituição brasileira analisada têm suas origens mais ligadas a setores técnicos que ao corpo político. Isso se expressa, por exemplo, pelo fato de que, embora o Portal e-Democracia tenha conseguido se instaurar dentro da Casa por mediação de alguns parlamentares que abraçaram a causa, tendo sido incialmente alocado no âmbito das Comissões, ele teve sua ideia gestada entre servidores da Câmara (MITOZO, 2013; FARIA, 2012). Não se defende, contudo, que os servidores são, exclusivamente, os fatores que condicionam todo o processo. Devem ser considerados o jogo e as regras da política por detrás desses atores, o que guia, finalmente, todas as ações. Afinal, fala-se de parlamentos, instituições políticas, burocráticas e, sobretudo, hierárquicas.

\section{Conclusão}

A adoção de tecnologias digitais não consiste apenas no mecanismo desenvolvido. Esse é um processo maior de mudança nos procedimentos políticos internos aos parlamentos, uma vez que "A participação política na internet não se relaciona apenas ao grau de sofisticação das ferramentas disponíveis" (MARQUES, 2011, p.116).

A partir da análise realizada, percebe-se que o sucesso de iniciativas para abertura dos 
parlamentos, instituições públicas, precisa necessariamente passar pelo comprometimento de servidores dos legislativos e da integração interna e externa de seus setores. Isso se faz necessário porque instabilidade organizacional no projeto, muitas vezes consequência de terceirização do desenvolvimento e da gestão de uma iniciativa institucional, é um dos fatores que podem trazer consequências negativas para experiências do setor público (CHADWICK, 2011). Desse modo, os recursos humanos e a infraestrutura de que as Casas analisadas dispunham foram elementos centrais, embora não os únicos, na elaboração e no desenvolvimento de iniciativas para a digitalização de atividades democráticas promovidas pelos Legislativos em análise, conforme previsto por Leston-Bandeira (2007).

Além disso, uma melhor integração entre setores contribuiria para uma publicidade de melhor qualidade, como mostra o caso brasileiro. A SECOM da Câmara dos Deputados é um órgão chave em relação à divulgação dos meios de abertura participativa da $\mathrm{CD}$. Os canais que esse setor gere têm potencial de alcance a todos os cidadãos, não apenas entre aqueles que já conhecem as iniciativas, como é o caso já apontado dos perfis do Portal e-Democracia. Nesse sentido, a ação da Casa dos Comuns de promover debates nas redes em que, a princípio, só serviam para divulgação, teria potencial para atingir um maior número de usuários que uma ferramenta menos exposta, como é o caso do e-Democracia brasileiro. Essa é a razão para as redes sociais digitais terem atraído tantas instituições dispostas a aproximar-se dos cidadãos, a fim de divulgar melhor suas ferramentas e atividades, como nos casos analisados em outros estudos (LESTON-BANDEIRA, 2009, 2012; CAMPOS-DOMÍNGUEZ, 2011; BRAGA; MITOZO; TADRA, 2016).

$\mathrm{O}$ projeto Câmara Itinerante do Brasil mostrou, entretanto, que a integração não é impossível, pois durante os trabalhos as ações se apresentaram bastante coordenadas entre setores. Essa relação foi complementar ao envolvimento da presidência da Casa nas atividades, uma vez que a presença desse ator político à época nas caravanas do referido projeto teve grande influência sobre o efeito agregador. Do mesmo modo, integrar as ações das equipes de PDS e POS às recomendações do DDC, como ocorreu na avaliação do que as atividades desse comitê acarretaram à Casa, se liga ao próprio interesse do presidente da Casa em promover essa integração. O próprio Speaker esteve presente na reunião que convocou um ano após o lançamento do relatório do DDC, em 2016.

Percebe-se que a integração entre os setores estaria mais ligada à qualidade estrutural da iniciativa, tendo em vista que pode haver uma contribuição coletiva para a melhoria das ferramentas quanto (1) à publicidade das ações desenvolvidas, e (2) ao compartilhamento de ideias acerca de canais que deveriam compor as ferramentas. Um grande passo em direção a essas parcerias, no caso brasileiro, foi a criação do Laboratório Hacker, em 2013, e a integração dos serviços de Cibercâmara na Casa dos Comuns britânica, embora ainda haja deficiência em outros pontos, como leis que podem realmente tornar essas ações parte do processo de tomada 
de decisão pública, o que levaria os projetos a outro nível, mais conectados à representação política.

\section{Referências}

AVRITZER, L. Instituições participativas e desenho institucional: algumas considerações sobre a variação da participação no Brasil democrático. Opinião Pública, Campinas, v. 14, n. 1, Junho, p.43-64, 2008.

BENHABIB, S. Democracy and difference: contesting the boundaries of the political. Princeton: Princeton University Press, p. 67-94, 1996.

BLASER, Lucinda. Entrevista, 2016. In: Mitozo, I.B. E-Participação nos Parlamentos: Desenvolvimento e uso de iniciativas pela Câmara dos Deputados brasileira e pela House of Commons britânica. Tese [Doutorado em Ciência Política]. Universidade Federal do Paraná. Programa de Pós-Graduação em Ciência Política. Curitiba, 2018.

BRAGA, S.; MITOZO, I.B.; TADRA, J. As funções educativas dos e-parlamentos: uma análise longitudinal do caso brasileiro. Cadernos de Pesquisa, Fundação Carlos Chagas, v.46, n.162, p. 1192-1215, 2016. DOI: 10.1590/198053143645.

BRANDÃO, Walternor; FARIA, Cristiano; RAVAZOLLI, Simone. Entrevista com gestores do LabHacker, 2017. In: Mitozo, I.B. E-Participação nos Parlamentos: Desenvolvimento e uso de iniciativas pela Câmara dos Deputados brasileira e pela House of Commons britânica. Tese [Doutorado em Ciência Política]. Universidade Federal do Paraná. Programa de Pós-Graduação em Ciência Política. Curitiba, 2018.

CÂMARA DOS DEPUTADOS. Comissão Legislativa de Participação. O menor caminho entre os interesses da população e a Câmara dos Deputados. $7^{a}$ ed. Brasília: Edições Câmara, 2013.

CAMPOS-DOMÍNGUEZ, Eva María. El desarrollo de la ciberdemocracia en el Congreso de los Diputados: la comunicación e interacción entre ciudadanos y parlamentarios a través de internet (2004-2008). Universidad Complutense de Madrid, Servicio de Publicaciones, 2011.

CHADWICK, A. Explaining the failure of an online citizen engagement initiative: The role of internal institutional variables. Journal of Information, Technology \& Politics, v.8, n.1, p.2140, 2011.

COLEMAN, S. New mediation and direct representation: reconceptualizing representation in the digital age. New media \& Society, v.7, n.2, p.177-198, 2005.

DIGITAL DEMOCRACY COMMISSION. Open Up! Report of the Speaker's Commission on Digital Democracy. House of Commons, January 2015. Disponível em: http://www.digitaldemocracy.parliament.uk/. Acesso em: 10/04/2021.

FARIA, C.F. S. O Parlamento aberto na era da internet: Pode o povo colaborar com o Legislativo na elaboração das leis? Brasília: Câmara dos Deputados, Edições Câmara, 2012.

FOX, Ruth. Engagement and Participation: What the Public want and how our politicians need to respond. Parliamentary affairs, v.62, n.4, pp.673-685, 2009.

GREEN, Tracy. Entrevista, 2016. In: Mitozo, I.B. E-Participação nos Parlamentos:

Desenvolvimento e uso de iniciativas pela Câmara dos Deputados brasileira e pela House of Commons britânica. Tese [Doutorado em Ciência Política]. Universidade Federal do Paraná. Programa de Pós-Graduação em Ciência Política. Curitiba, 2018.

LESTON-BANDEIRA, C. The Impact of the Internet on Parliaments: A Legislative Studies Framework. Parliamentary Affairs, v. 50, n. 4, Ago/2007, pp. 665-674.

LESTON-BANDEIRA, C. Parliamentary functions portrayed on European parliaments' 
websites. Revista de Sociologia e Política, Curitiba, v. 17, n. 34, out. 2009, p. 13-27. LESTON-BANDEIRA, C. Towards a trustee model? Parliamentary representation in the internet era: the Portuguese case. Parliamentary Affairs, v. 65, n. 2, p. 425-447, 2012.

LESTON-BANDEIRA, C. The Pursuit of Legitimacy as a Key Driver for Public Engagement: The European Parliament Case. Parliamentary Affairs, v.67, p.415-436, 2014.

LESTON-BANDEIRA, C. Why symbolic representation frames parliamentary public engagement. British Journal of Politics, 2016. DOI: 10.1177/1369148115615029.

LESTON-BANDEIRA, C.; THOMPSON, L. Truly Engaging Citizens with the Parliamentary Process? An Evaluation of Public Reading Stage in the House of Commons. 20th Workshop of Parliamentary Scholars and Parliamentarians, Wroxton College, Oxfordshire, 25-26 July 2015.

MARQUES, F.P.J.A. Participação política e internet: meios e oportunidades digitais de participação civil na democracia contemporânea, com um estudo do caso do Estado brasileiro. Tese [Doutorado em Comunicação e Cultura Contemporâneas]. Salvador: UFBA, Faculdade de Comunicação, 2008.

MARQUES, F.P.J.A. Participação, instituições políticas e internet: um exame dos canais participativos presentes nos portais da Câmara e da Presidência do Brasil. In: MAIA, R.C.M.; GOMES, W.; MARQUES, F.P.J.A. Internet e Participação Política no Brasil. Porto Alegre: Sulina, 2011, pp. 95-122.

MITOZO, I.B. Participação e deliberação em ambiente online: um estudo do Portal eDemocracia. Dissertação [Mestrado em Comunicação], Universidade Federal do Ceará, 2013.

MITOZO, I.B. E-Participação nos Parlamentos: Desenvolvimento e uso de iniciativas pela Câmara dos Deputados brasileira e pela House of Commons britânica. Tese [Doutorado em Ciência Política]. Universidade Federal do Paraná. Programa de Pós-Graduação em Ciência Política. Curitiba, 2018. 267p.

MITOZO, I.B. A utilização de sistemas deliberativos remotos pelas Assembleias Legislativas brasileiras durante a pandemia de COVID-19: Características e prospectos. Revista do Legislativo Paranaense, Curitiba, n. 4, Ago/2020, p. 9-24.

MUNDKUR, A.; VENKATESH, M. The Role of Institutional Logics in the Design of EGovernance Systems. Journal of Information Technology \& Politics, v.6, n.1, p.12-30, 2008.

PEIXOTO, Tiago. Virtual parliaments in Times of Coronavirus: Flattening the Authoritarian Curve? 2020. Disponível em: https://democracyspot.net/2020/04/21/virtual-parliaments-intimes-of-coronavirus-flattening-the-authoritarian-curve/. Acesso: 10/04/2021.

PRIOR, A. "This infinite variety of forms": how Parliament, and political science, can better understand and encourage political engagement through the use of narratives. Trabalho apresentado no Encontro Anual da Political Studies Association, Glasgow - UK, 10-12 de Abril, 2017.

ROMANELLI, Mauro. Towards sustainable parliaments. In: BRĂTIANU, C.; ZBUCHEA, A.; PÎNZARU, F.; VĂTĂMĂNESCU, E.M.; LEON, R.D. (eds.). Proceedings of Strategica, III International Academic Conference, Bucharest, Romania, p. 636- 646, 29-30 de Outubro, 2015.

VEIGA, L.; GONDIM, S. M. G. A Utilização de Métodos Qualitativos na Ciência Política e no Marketing Político. Opinião Pública, Campinas, v. 7, n.1, pp. 1-15, 2001.

Artigo submetido em: 2021-04-27; Artigo reapresentado em: 2021-05-06; Artigo aceito em: 2021-05-12 